\title{
EQUILÍBRIO QUÍMICO E CINÉTICA ENZIMÁTICA DA INTERAÇÃO DE $\alpha$-AMILASE COM COMPOSTOS FENÓLICOS ENCONTRADOS EM CERVEJA
}

\author{
George Augusto V. de Oliveira* e José Maurício Schneedorf Ferreira da Silva \\ Departamento de Bioquímica, Universidade Federal de Alfenas, 37130-000 Alfenas - MG, Brasil
}

Recebido em 25/11/2016; aceito em 02/03/2017; publicado na web em 19/05/2017

\begin{abstract}
CHEMICAL EQUILIBRIUM AND ENZYMATIC KINETICS OF $\alpha$-AMYLASE INTERACTION WITH PHENOLIC COMPOUNDS FOUND IN BEER. $\alpha$-amylase is a key enzyme in the production of beer due to the breakdown of starch into fermentable sugars. During the preparation of the brewing mash, the enzyme can be affected by polyphenols present in the mixture. Our aim was to evaluate the kinetics and equilibrium of the interaction of $\alpha$-amylase with some polyphenols (chlorogenic, caffeic, ferulic acids and quercetin) present in beer in the usual range of mashing temperatures $\left(40-80{ }^{\circ} \mathrm{C}\right)$, and to treat the results with integrated Michaelis-Menten and Stern-Volmer equations. The results showed a competitive inhibition model for all compounds with $\mathrm{Ki}$ values around 30 umol.L-1. The binding constants $(\mathrm{Kb})$ revealed increasing values with temperature up to $323 \mathrm{~K}$, corroborating the enzymatic data. Values for $\Delta \mathrm{H}$ and $\Delta \mathrm{S}$ revealed an entropy-driven association mechanism. Structure-activity relationships demonstrated a positive correlation between the biological activity of $\alpha$-amylase and the polar nature descriptors of the polyphenols. Binding assays of the enzyme with chlorogenic acid at different $\mathrm{pH}$ and ionic strength support the structure-activity and thermodynamic data and suggest a plausible interaction of the carboxylate ion of the ligand with basic groups in the vicinity of the catalytic site of the enzyme.
\end{abstract}

Keywords: $\alpha$-amylase; polyphenols; binding; kinetic; beer.

\section{INTRODUÇÃO}

As $\alpha$-amilases estão entre as mais importantes enzimas industriais, amplamente utilizadas em indústrias na produção de maltodextrinas, panificação, álcool, detergentes, têxteis e, em especial, para fabricação de cerveja. ${ }^{1}$

Segundo dados do SEBRAE (Serviço Brasileiro de Apoio às Micros e Pequenas Empresas) e SINDCERV (Sindicato Nacional das Indústrias de Cerveja), o Brasil é o $3^{\circ}$ maior mercado consumidor de cerveja, com produção de 13 bilhões de litros e consumo de 14 bilhões de litros, resultando em 62 litros per capita. ${ }^{2}$ Porém, ao mesmo tempo em que as maiores empresas cervejeiras do mundo estão inseridas nesse mercado, produzindo basicamente cervejas altamente populares como as American Lager, têm surgido como opção as cervejas especiais, também conhecidas como artesanais ou Premium. ${ }^{3}$

A produção da cerveja a partir do malte de cevada consiste em um exemplo complexo de enzimologia aplicada. Durante a preparação da cerveja, a ação enzimática que ocorre no preparo do mosto aquecido sob influência de diversos compostos pode levar a um produto final diversificado em propriedades organolépticas, em paralelo aos processos industriais de refinamento e controle de fermentação da cerveja. A ação enzimática nessa etapa promove a degradação do amido em açúcares fermentáveis. Interferências físicas (ex: alterações de rampas de aquecimento, ordem na adição de produtos) ou químicas (inibição de enzimas degradantes) podem alterar a disponibilidade de açúcares fermentáveis e as características finais da cerveja. ${ }^{4}$

As enzimas $\alpha$-amilase e $\beta$-amilase são as principais responsáveis pela formação de açúcares fermentáveis durante a produção de mosto. A $\alpha$-amilase catalisa a hidrólise das ligações $\alpha$-1,4-glucano internas em polissacaridios contendo três ou mais unidades de D-glicose. Em contraste, a $\beta$-amilase atua sobre a ligação entre os últimos dois e três resíduos de glicose na cadeia de amido, liberando maltose. ${ }^{5}$

O mecanismo catalítico de $\alpha$-amilases segue um padrão

\footnotetext{
*e-mail: george_veloso@yahoo.com.br
}

similar entre várias espécies, ${ }^{6}$ entre as quais $\alpha$-amilase pancreática e salivar humana, de Aspergillus niger, Hordeum vulgare (cevada), e Aspergillus oryzae. Cada enzima possui um resíduo de glutamato (Glu) e dois resíduos de aspartato (Asp) necessários para a atividade, enquanto a maioria das enzimas da família também contêm dois resíduos de histidina (His) críticos para a estabilização do estado de transição. ${ }^{6}$

A inibição da $\alpha$-amilase pode ocorrer por fatores internos ou externos ao meio, tais como variações da temperatura, variações de $\mathrm{pH}$, aumento da concentração de açúcares redutores (maltose e glucose) e interação com diversos compostos, entre outros..$^{7-9}$

Componentes fenólicos são adicionados à cerveja por lúpulo e malte. Eles exercem uma influência sobre vários atributos de qualidade da cerveja, tais como cor, sabor, adstringência e estabilidade coloidal da cerveja. ${ }^{10,11}$ Os polifenóis que ocorrem naturalmente na cerveja são membros das proantocianidinas, oligômeros e polímeros de catequinas, epicatequina, e galocatequina; ou monômeros, como ácido cafeico, ácido ferúlico, ácido clorogênico e quercetina, os quatro últimos avaliados neste trabalho. ${ }^{12}$

A atividade de uma enzima pode ser determinada com base na velocidade de conversão do substrato em produto pela ação da enzima, o que pode ser obtido convencionalmente variando-se a concentração de substrato. Alternativamente, essa taxa de reação também pode ser obtida por integração da equação de Michaelis-Menten (Equação 1), permitindo a determinação dos parâmetros catalíticos a partir de um único ensaio, otimizando tempo, reagentes e substratos. Essa determinação se dá por ajuste não linear de modelos cinéticos aos dados de uma curva progressiva de formação do produto ou de decaimento do substrato ao longo do tempo. ${ }^{13}$ Ajustes não lineares possuem vantagens sobre o tratamento linear de dados de catálise enzimática (ex: Lineweaver-Burk, Eadie-Hofstee, entre outros. ${ }^{13}$ uma vez que não há transformação das variáveis originais $(t, S t)$, não se fere premissas de independências de variáveis para ajustes lineares (ex: Eadie-Hofstee), e tampouco produzem dispersões assimétricas dos erros (ex: Lineweaver-Burk). 
$t=\frac{1}{V \max } *\left(K m * \log \left(\frac{[S t]}{[S o]}\right)+([S t]-[S o])\right)$

Onde t representa o tempo, Vmax representa a velocidade máxima da reação, Km é a constante de Michaelis-Menten para afinidade da enzima pelo substrato, [St] é a concentração do substrato e [So] é a concentração do substrato no tempo zero.

Os inibidores reversíveis podem ser basicamente divididos em competitivos (Equação 2), incompetitivos (Equação 3) e não-competitivos (Equação 4), representadas pelas equações integradas que seguem. ${ }^{14}$

$$
\begin{aligned}
& t=\frac{1}{V \max } *\left(K m *\left(1+\frac{I}{K i c}\right) * \log \left(\frac{[S t]}{[S o]}\right)+([S t]-[S o])\right) \\
& t=\frac{1}{V \max } *\left(K m * \log \left(\frac{[S t]}{[S o]}\right)+\left(1+\frac{I}{K i u}\right) *([S t]-[S o])\right) \\
& t=\frac{1}{V \max } *\left(K m *\left(1+\frac{I}{K i c}\right) * \log \left(\frac{[S t]}{[S o]}\right)+\left(1+\frac{I}{K i u}\right) *([S t]-[S o])\right)
\end{aligned}
$$

Tais equações são deduzidas a partir da Equação 1, onde o termo $\left(1+\frac{I}{K i c}\right)$ ou $\left(1+\frac{I}{K i u}\right)$ representa a contribuição do efeito inibitório, Kic a constante de inibição competitiva e Kiu a constante de inibição incompetitiva.

\section{Determinação de parâmetros de interação de ligantes com proteínas por espectrofluorimetria}

A $\alpha$-amilase apresenta intensidade de fluorescência decorrente de seus fluoróforos intrínsecos (triptofano, tirosina e fenilalanina). Na prática, o triptofano é o fluoróforo intrínseco dominante, e alterações nos espectros de emissão do triptofano podem estar ligadas a transições conformacionais, associação de subunidades, ligação ao substrato ou desnaturação. Essas interações podem afetar o ambiente local na circunvizinhança do anel indol. ${ }^{15} \mathrm{~A}$ intensidade de fluorescência de uma proteína pode ser diminuída como resultado de uma ampla variedade de processos. Tais declínios na intensidade podem ser resultados de diferentes interações moleculares entre a proteína e o ligante. ${ }^{16}$

Os mecanismos de extinção da fluorescência podem ser avaliados pela relação de Stern-Volmer conforme a Equação 5, onde $F_{0}$ e $F$ representam as intensidades de fluorescência da proteína na ausência e na presença de ligante, respectivamente, $[Q]$ a concentração do ligante, $k_{q}$ a constante da interação bimolecular, $\tau_{0}$ o tempo de vida do fluoróforo na ausência do ligante, e $K_{s v}$ a constante de interação de Stern-Volmer. ${ }^{15}$

$$
\frac{\boldsymbol{F}_{0}}{\boldsymbol{F}}=\boldsymbol{K}_{q} \tau_{0}[Q]=1+\boldsymbol{K}_{s v}[Q]
$$

No caso das extinções serem puramente estáticas (formação de complexo) ou dinâmicas (colisional), a representação gráfica mostra-se linearmente dependente; entretanto, se a interação ocorrer de forma mista entre estática e dinâmica, o gráfico de Stern-Volmer mostra-se dependente exponencialmente. ${ }^{17} \mathrm{Em}$ experimentos de interação ligante-proteína, o valor de $K_{s v}$ é comumente considerado como a constante de interação do complexo $\left(K_{b}\right){ }^{18,19}$

Diante do exposto, este trabalho avaliou as possíveis interações moleculares e interferência inibitória de polifenóis usualmente presentes no mosto cervejeiro com $\alpha$-amilase, e em temperaturas compatíveis com o processamento desse. Para tanto, foram realizados ensaios de inibição enzimática e equilíbrio químico de $\alpha$-amilase com polifenóis em temperaturas de $25^{\circ}$ a $60{ }^{\circ} \mathrm{C}$, e os resultados relacionados à estrutura dos polifenóis e da enzima.

\section{PARTE EXPERIMENTAL}

\section{Materiais}

Todos os reagentes utilizados nesse trabalho foram de grau analítico. Foi empregado como substrato o amido solúvel (VETEC, Rio de Janeiro, RJ, Brasil), e como enzima $\alpha$-amilase de Aspergillus oryzae (Sigma-Aldrich, St.Louis, MA, EUA). Os polifenóis escolhidos foram o ácido cafeico (Sigma-Aldrich, St.Louis, MA, EUA), ácido clorogênico (Sigma-Aldrich, St.Louis, MA, EUA), quercetina (Sigma-Aldrich, St. Louis, MA, EUA) e ácido ferúlico (SigmaAldrich, St. Louis, MA, EUA), todos de grau P.A.

A pureza da enzima foi testada a partir do seu coeficiente de extinção molar e perfil de absorção molecular, esse também utilizado para que se verifique o grau de pureza dos polifenóis.

\section{Ensaio de inibição enzimática de $\alpha$-amilase com compostos fenólicos}

A cinética enzimática da $\alpha$-amilase foi testada na ausência e na presença dos polifenóis. Utilizamos o método modificado de amido-iodo como ensaio de referência. A solução de amido foi preparada em uma concentração de $20 \mathrm{mg} \mathrm{mL}^{-1}$ e diluída em uma proporção de 1:1 com um tampão fosfato de potássio $0,04 \mathrm{~mol} \mathrm{~L}^{-1} \mathrm{pH} 5,9$. O reagente de revelação foi preparado por diluição em 100:1 da solução estoque de lugol (500 mg de iodo e 5,0 g de iodeto de potássio/100 mL de água).

Uma alíquota de $1 \mathrm{~mL}$ de solução de amido foi adicionada a um tubo de ensaio contendo $0,5 \mathrm{~mL}$ de tampão fosfato de potássio 0,04 $\mathrm{mol} \mathrm{L}^{-1}$ e incubado durante $10 \mathrm{~min}$ em banho-maria HMO128D (Hemoquímica, Minas Gerais, Brasil) (298 K, 313 K e 323 K), e a temperatura da solução foi aferida por um termômetro digital MT-600 (Minipa, São Paulo, Brasil). A enzima (30 $\mu \mathrm{L}$ a concentração de $1 \mathrm{mg} \mathrm{mL}^{-1}$ ) foi previamente incubada com uma alíquota do composto fenólico durante 10 minutos, sendo posteriormente adicionada na solução de substrato sob as condições do ensaio. Após intervalos de 30 segundos, alíquotas de $50 \mu \mathrm{L}$ foram retiradas do sistema tampão/ amido/enzima/composto fenólico, seguindo-se a adição de $1 \mathrm{~mL}$ de reagente de interrupção $\left(\mathrm{HCl}, 0,05 \mathrm{~mol} \mathrm{~L}^{-1}\right)$. Após homogeneização, adicionou-se $100 \mu \mathrm{L}$ de solução de iodo.

O decaimento do sinal do substrato foi monitorado em um espectrofotômetro Libra S22 UV/Vis (Biochrom LKB, St Albans, Reino Unido) em temperatura de $25^{\circ} \mathrm{C}$. A temperatura da solução foi aferida por um termômetro digital MT-600 (Minipa, São Paulo, Brasil).

\section{Espectrofluorimetria da interação de $\alpha$-amilase com compostos fenólicos}

Os ensaios para obtenção de parâmetros termodinâmicos da interação da $\alpha$-amilase com os polifenóis foram realizados em um fluorofotômetro CaryEclipse Spectro (Varian, Austrália) conectado a um banho de circulação de água modelo Q214-SC (Quimis, São Paulo, Brasil) com programação de rampas de temperatura controlada por microprocessador. Os dados coletados foram obtidos a temperaturas de solução constante de 293, 303, 313, 323 e 333 K. A temperatura da solução foi aferida por um termômetro digital MT-600. As amostras foram excitadas em $280 \mathrm{~nm}$ e a emissão de fluorescência, medida em 90 graus em relação ao feixe de excitação, foi registrada na faixa de 290-500 nm. Os dados obtidos foram corrigidos para o efeito interno segundo Van De Weert e Stella. ${ }^{19}$ 


\section{RESULTADOS E DISCUSSÃO}

\section{Cinética de $\alpha$-amilase na presença de compostos fenólicos}

As curvas progressivas de consumo de substrato por $\alpha$-amilase na presença de ácido cafeico, ácido ferúlico, quercetina e ácido clorogênico em diferentes temperaturas estão ilustrados na Figura 1.

A inibição da enzima pelos polifenóis foi dependente da temperatura a um valor ótimo de $323 \mathrm{~K}$, embora apenas o ácido clorogênico tenha sido capaz de inibir a enzima em 298 K. Ajustes não lineares das equações 2, 3 e 4 aos dados experimentais a $323 \mathrm{~K}$ foram realizados, e os resultados estão representados na Tabela 1 .

Avaliou-se o melhor modelo comparando-se os resultados obtidos e o erro inerente a cada um, bem como a magnitude dos parâmetros cinéticos encontrados na ausência dos compostos fenólicos. Pelos dados da Tabela 1, pode-se verificar que o modelo de inibição competitiva foi o que melhor se ajustou aos dados. Uma sobreposição dos valores teóricos desse modelo aos dados está representada na Figura 2.

\section{Efeito da temperatura}

Os dados cinéticos obtidos também podem ser representados por um decaimento exponencial de $1^{\mathrm{a}}$ ordem, obtido pela lei de velocidade integradas, como dado pela Equação 6 a seguir. ${ }^{20}$

$$
[S]=\left[S_{0}\right] e^{-k t}
$$

A partir da equação 6 realizou-se um ajuste exponencial de $1^{\text {a }}$ ordem aos dados experimentais a fim de se obter a constante de velocidade $(k)$. A partir do valor de " $k$ ", pode-se analisar a dependência da velocidade de reação com a temperatura pela relação de Arrhenius. ${ }^{20}$

$$
\ln k=\ln A-\frac{E_{a}}{R T}
$$

Em que $k$ representa a constante de velocidade, $A$ a constante pré-exponencial ou fator de frequência, $E_{a}$ a energia de ativação, $R$ a constante dos gases $\left(8,314 \mathrm{~J} \mathrm{~K}^{-1} \mathrm{~mol}^{-1}\right)$ e $T$ a temperatura.

Os resultados apresentados na Figura 3 reforçam a complexação com ácido clorogênico como a mais sensível à temperatura entre as testadas.

Os valores para a energia de ativação $\left(\mathrm{E}_{a}\right)$ da reação para o sistema enzima-inibidor-substrato estão apresentados na Tabela 2.

Esses resultados estão de acordo com os obtidos a partir da cinética de inibição realizada para os compostos fenólicos em $323 \mathrm{~K}$, e apresentaram valores de energia de ativação para ácido clorogênico > ácido ferúlico > ácido cafeico > quercetina. O ácido clorogênico foi o que apresentou menor valor de Kic (Tabela 1), maior sensibilidade com a temperatura (Tabela 2) e maior inibição na temperatura ótima da enzima (323 K, Figura 2), antagonicamente aos valores apresentados para a quercetina. Isso pode ser justificado pela maior área de superfície apolar da quercetina, quando comparada à do ácido clorogênico, reduzindo sua interação, e/ou a presença do carboxilato desse, reforçando a mesma. De fato, é referido que a inibição de $\alpha$-amilase, de modo geral, decorre da interação de grupos polares com o bolso catalítico relativamente pequeno da enzima. ${ }^{21}$
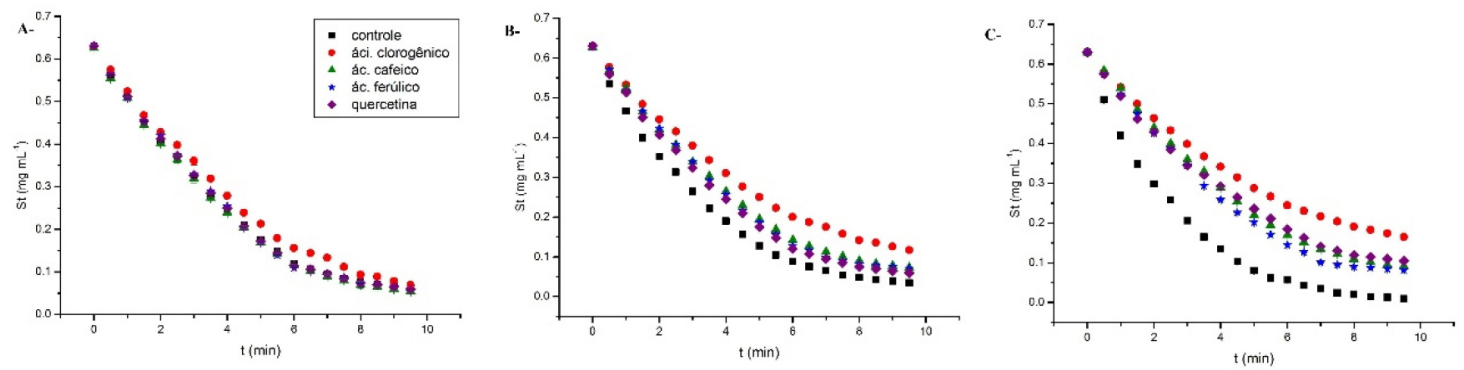

Figura 1. Inibição enzimática de compostos fenólicos a 2,8 $\times 10^{-5} \mathrm{~mol} \mathrm{~L}^{-1}$ sobre $\alpha$-amilase. A - $298 \mathrm{~K}$, B - $313 \mathrm{~K}$, Figura C-323 K

\begin{tabular}{|c|c|c|c|c|}
\hline Polifenol & Parâmetro cinético & Inibição competitiva & Inibição incompetitiva & Inibição não competitiva pura \\
\hline & $\mathrm{Km}$ & $1,45 \pm 0,19$ & $131 \pm 719$ & $8,64 \pm 2,18$ \\
\hline \multirow[t]{3}{*}{ Ácido clorogênico } & Vmax & $0,69 \pm 0,08$ & $54,9 \pm 301$ & $3,79 \pm 0,91$ \\
\hline & $\mathrm{Ki}$ & $2,00 \times 10^{-5} \pm 4,50 \times 10^{-7}$ & $1,40 \times 10^{-4} \pm 7,60 \times 10^{-7}$ & $6,20 \times 10^{-5} \pm 2,30 \times 10^{-6}$ \\
\hline & $\mathrm{Km}$ & $1,26 \pm 0,24$ & $152 \pm 989$ & $8,17 \pm 1,75$ \\
\hline \multirow[t]{3}{*}{ Ácido cafeico } & Vmax & $0,62 \pm 0,10$ & $64,3 \pm 416$ & $3,62 \pm 0,74$ \\
\hline & $\mathrm{Ki}$ & $3,60 \times 10^{-5} \pm 9,70 \times 10^{-7}$ & $8,81 \times 10^{-5} \pm 5,40 \times 10^{-4}$ & $4,23 \times 10^{-5} \pm 1,32 \times 10^{-6}$ \\
\hline & $\mathrm{Km}$ & $1,27 \pm 0,38$ & $152 \pm 989$ & $8,17 \pm 1,75$ \\
\hline \multirow[t]{3}{*}{ Ácido ferúlico } & $V \max$ & $0,62 \pm 0,16$ & $64,3 \pm 416$ & $3,62 \pm 0,74$ \\
\hline & $\mathrm{Ki}$ & $4,52 \times 10^{-5} \pm 2,24 \times 10^{-6}$ & $1,90 \times 10^{-4} \pm 9,35 \times 10^{-7}$ & $5,42 \times 10^{-5} \pm 2,31 \times 10^{-6}$ \\
\hline & $\mathrm{Km}$ & $1,47 \pm 0,37$ & $\mathrm{SC}$ & $14,5 \pm 5,95$ \\
\hline \multirow[t]{2}{*}{ Quercetina } & Vmax & $0,75 \pm 0,15$ & $\mathrm{SC}$ & $6,30 \pm 2,50$ \\
\hline & $\mathrm{Ki}$ & $3,30 \times 10^{-5} \pm 1,44 \times 10^{-6}$ & $\mathrm{SC}$ & $5,92 \times 10^{-4} \pm 1,63 \times 10^{-6}$ \\
\hline
\end{tabular}

Tabela 1. Valores de ajuste simultâneo (controle e teste) para inibição competitiva, inibição incompetitiva e inibição não competitiva pura dos polifenóis em 323K

*SC - Sem convergência do algoritmo de regressão não linear (Gauss-Newton). 


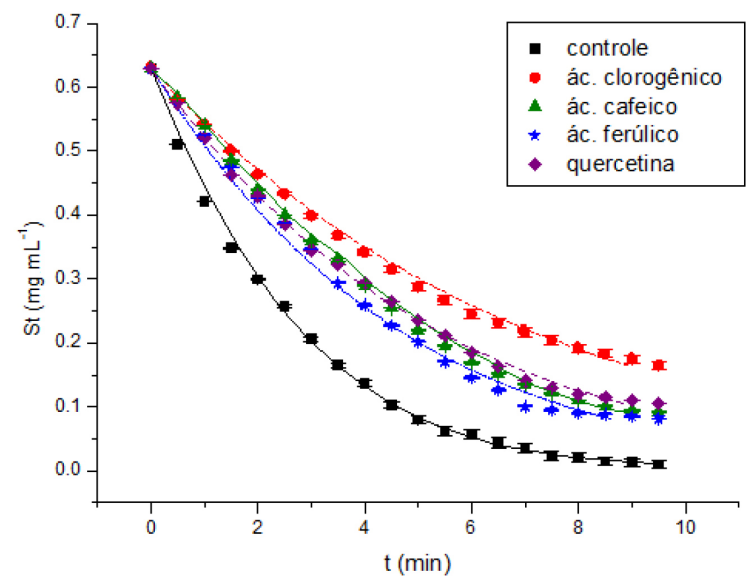

Figura 2. Ajuste não linear dos dados de inibição dos compostos fenólicos (ácido clorogênico, ácido cafeico, ácido ferúlico e quercetina) sobre a catálise de amido por $\alpha$-amilase em pH 5,9 a $323 \mathrm{~K}$ para determinação de valor do Kic

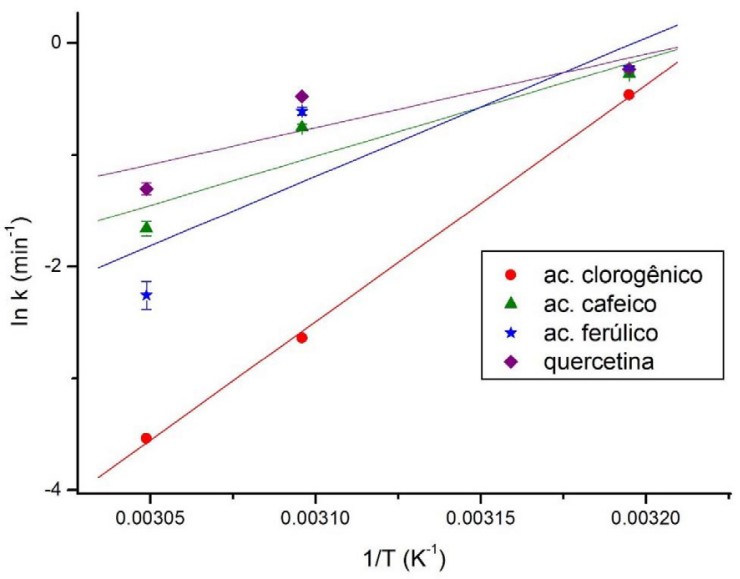

Figura 3. Dependência da constante de velocidade ( $k$ ) da reação inibitória de polifenóis sobre a catálise do amido por $\alpha$-amilase com a temperatura
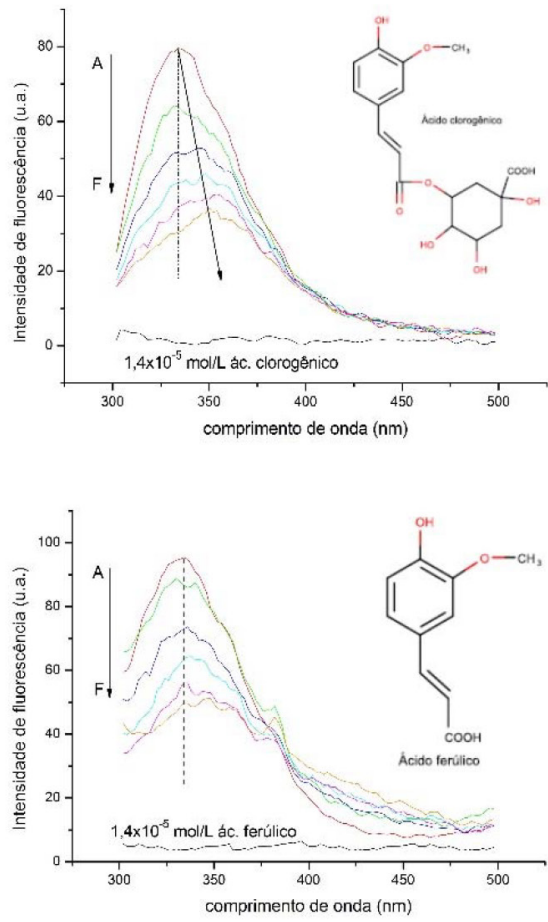

Tabela 2. Energia de ativação da reação inibitória de polifenóis sobre a catálise do amido por $\alpha$-amilase

\begin{tabular}{lc}
\hline Composto fenólico & $\mathrm{E}_{a}\left(\mathrm{~kJ} \mathrm{~mol}^{-1}\right)$ \\
\hline Controle & $31,8 \pm 3,72$ \\
Ácido clorogênico & $176 \pm 5,95$ \\
Ácido cafeico & $72,8 \pm 28,9$ \\
Ácido ferúlico & $103 \pm 52,4$ \\
Quercetina & $54,7 \pm 20,7$ \\
\hline
\end{tabular}

\section{Interação de $\alpha$-amilase com os compostos fenólicos por espectrofluorimetria}

A Figura 4 exibe os espectros de emissão de fluorescência da $\alpha$-amilase na ausência e na presença dos compostos fenólicos, nos quais é observada uma forte banda de emissão de fluorescência em $334 \mathrm{~nm}$ apresentado pela $\alpha$-amilase. Os ligantes não apresentaram fluorescência intrínseca no comprimento de onda de excitação de $280 \mathrm{~nm}$ para a faixa espectral ensaiada. Essa emissão de fluorescência da enzima é devida à presença de seus resíduos aromáticos, em especial a 12 resíduos de triptofano presentes na estrutura da $\alpha$-amilase (UniProtKB/Swiss-Prot - código P0C1B3). ${ }^{22}$ Especificamente, o domínio catalítico da enzima apresenta um resíduo de Trp-83 localizado no subsítio $-3 .^{21}$

Em todos os espectrofluorogramas apresentados na Figura 4, a intensidade de fluorescência da $\alpha$-amilase sofreu uma gradual diminuição com o aumento da concentração de ligante. A elevada diminuição da intensidade fluorescência sugere que ocorreu a formação de complexos entre eles, ${ }^{23}$ o que é corroborado pelos resultados de inibição da enzima.

Nota-se que houve um deslocamento batocrômico (red shift) do espectro de fluorescência do complexo formado indicado pelas setas da figura 3 para a interação com ácido clorogênico e/ou ácido cafeico com a enzima. O red shift do comprimento de onda de
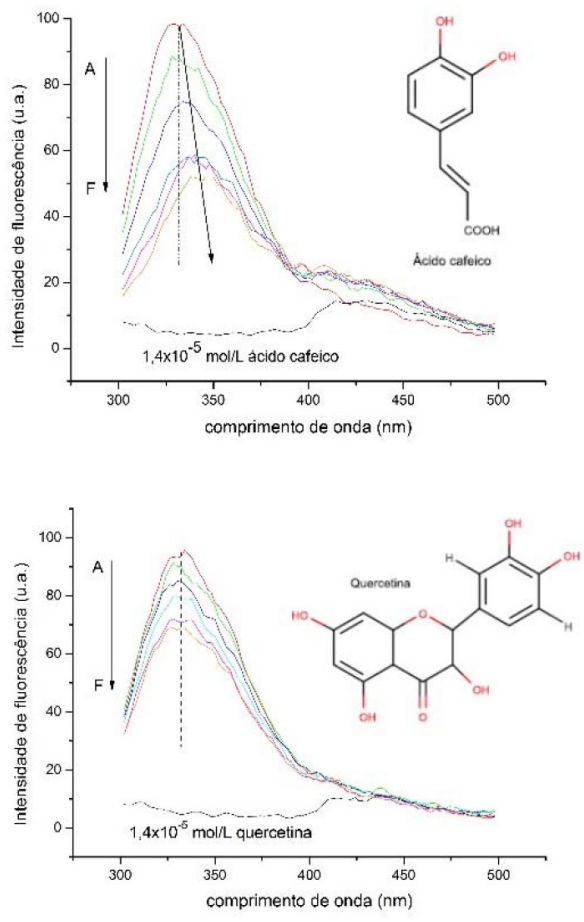

Figura 4. Espectro de emissão de fluorescência da $\alpha$-amilase na ausência e presença de compostos fenólicos em várias concentrações, $A$-F: de 0 a 1,4x $10^{-5}$ mol $L^{-1}$ com incrementos de $2,8 \times 10^{-6} .\left(T=323 \mathrm{Ke} \lambda_{e x}=280 \mathrm{~nm}\right)$ 
emissão máxima de 334 para $348 \mathrm{~nm}$ da $\alpha$-amilase na presença de ácido clorogênico e de 334 para $342 \mathrm{~nm}$ da $\alpha$-amilase na presença de ácido cafeico, respectivamente, pode caracterizar um aumento da polaridade (ou uma diminuição da hidrofobicidade) na região vizinha ao sítio de triptofano, sugerindo uma transição conformacional na enzima. ${ }^{24}$ Contrariamente, não foi verificado nenhum desvio para a interação de $\alpha$-amilase na presença de ácido ferúlico ou quercetina.

Embora seja especulativo, ambas as estruturas apresentam uma maior característica hidrofóbica (grupo metileno no ácido ferúlico e maior superfície apolar na quercetina) quando comparado aos demais testados, o que pode relacionar-se com uma menor energia de ligação com a enzima.

$O$ efeito da interação entre a $\alpha$-amilase e os ligantes foi quantitativamente abordado pela equação 5 de Stern-Volmer, e está representado na Figura 5.

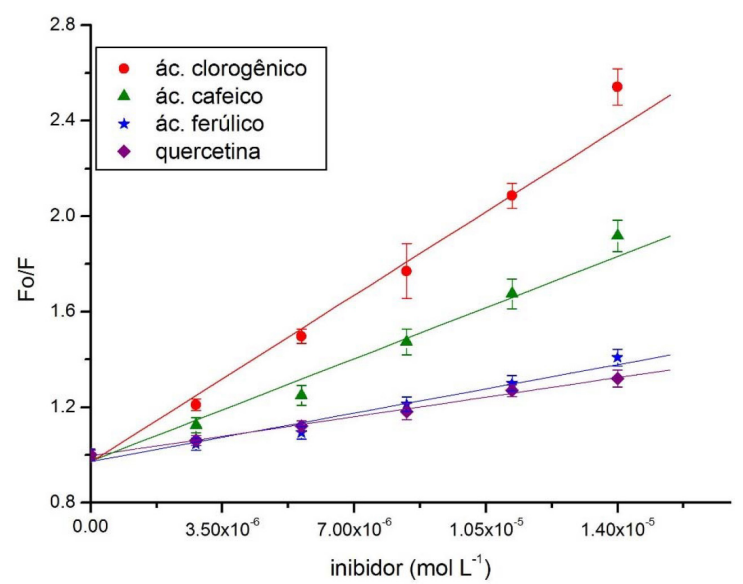

Figura 5. Gráfico de Stern-Volmer da interação de $\alpha$-amilase com os polifenóis. $T=323 \mathrm{~K}$

Esses resultados mostram uma tendência linear com a concentração dos polifenóis, sugerindo um comportamento estático (interação) ou dinâmico (colisional) para a extinção observada. Embora essa distinção possa ser apenas comprovada fluorimetricamente por determinação da constante de tempo de vida do fluoróforo $\left(\tau_{0}\right)$ em diferentes temperaturas, ${ }^{15}$ o potencial inibitório dos polifenóis atesta o caráter estático do fenômeno.

Utilizando dados obtidos para a constante de interação dos complexos $\left(K_{b}\right)$ em diferentes temperaturas, os parâmetros termodinâmicos foram calculados a partir da equação 8 para energia de Gibbs $(\Delta G)$ e equação 9 de Van't Hoff para a variação da entalpia $(\Delta H)$ e variação da entropia $(\Delta \mathrm{S}) .{ }^{16}$ Os dados estão representados na Tabela 3.

$$
\begin{gathered}
\Delta G^{\circ}=-R T \ln K_{b} \\
\ln K_{b}=-\left(\frac{\Delta H}{R}\right)\left(\frac{1}{T}\right)+\frac{\Delta S}{R}
\end{gathered}
$$

A energia de Gibbs dos complexos formados apoia uma maior interação para o ácido clorogênico, e menor interação para a quercetina, corroborando com os dados cinéticos apresentados. Valores positivos para $\Delta \mathrm{S}$ podem indicar uma desordem parcial na estrutura do solvente, pela exclusão das moléculas de água próximas ao sítio de interação do complexo. ${ }^{25}$ Adicionalmente, valores positivos para $\Delta \mathrm{He} \Delta \mathrm{S}$ estão relacionados a interações iônicas, plausíveis de ocorrer entre os carboxilatos do ácido clorogênico (pK 3,35), ácido cafeico (pK 4,37) e ácido ferúlico (pK 4,58) no pH 5,9 dos ensaios, ${ }^{26,27}$ com cadeias laterais de histidina, lisina e arginina na macromolécula. Isso sugere um mecanismo entropicamente dirigido da associação, contrapondo-se à contribuição entálpica relacionada à formação e quebra de ligações de hidrogênio, às interações de Van der Waals, e aos efeitos de protonação que podem acompanhar a associação. ${ }^{25} \mathrm{De}$ fato, o domínio catalítico de $\alpha$-amilase de Aspergillus oryzae exibe resíduos de aminoácidos básicos próximos ao subsítio de clivagem do substrato $(-3 \mathrm{a}+3) .{ }^{21}$ Complementarmente, isso poderia sugerir uma interação dos grupos aminados desses resíduos com íons carboxilatos de ácido clorogênico (menor valor de pKa), ácido ferúlico e cafeico (valores intermediários de $\mathrm{pKa}$ ) e, em menor grau, com quercetina (valores de pKa elevados, 7,4 e 8,2, para os fenóis). ${ }^{28}$

\section{Relação estrutura-atividade dos complexos}

A partir dos resultados de cinética e equilíbrio, que sugerem a magnitude do efeito biológico relacionado a determinadas propriedades dos ligantes, buscou-se analisar a relação da atividade biológica e formação dos complexos com alguns parâmetros reportados para os mesmos. Parâmetros como polarizabilidade, lipofilicidade, área total de superfície polar (TPSA) encontrados em base de dados dos compostos,${ }^{29}$ foram contrastados com o parâmetro de atividade inibitória da catálise, $I C_{50}$ (concentração do inibidor que fornece metade da inibição máxima), obtido a partir da Equação 10 para inibição competitiva, ao passo que valores de $\mathrm{pKa}$ encontrados na literatura foram contrastados com a constante de interação do complexo $\left(K_{b}\right) .^{30}$ Os resultados que apresentaram correlação significativa entre os descritores e os parâmetros biológicos avaliados $\left(I C_{50}\right.$ e $\left.K_{b}\right)$ estão apresentados na Figura 6.

$$
I C_{50}=K i c *\left(1+\frac{[S t]}{K m}\right)
$$

Com base nesses resultados pode-se afirmar que houve uma correlação positiva entre a atividade biológica (ligação e catálise) da $\alpha$-amilase com os descritores de natureza polar dos polifenóis (redução com lipofilicidade, aumento com polarizabilidade, TPSA e pKa). Esses resultados também corroboram com um mecanismo plausível de interação do íon carboxilato dos polifenóis com o sítio ativo da enzima como já sugerido. A fim de se testar essa hipótese, procedeu-se a avaliação espectrofluorimétrica da interação de $\alpha$-amilase em $323 \mathrm{~K}$ com o ácido clorogênico como modelo, variando-se pH (3,0 a 10,0) e força iônica $(\mathrm{NaCl}, 0$ a 10\%). Os resultados estão apresentados na Figura 7.

Tabela 3. Constante de ligação e parâmetros termodinâmicos da interação de $\alpha$-amilase com polifenóis

\begin{tabular}{lccccc}
\hline Polifenol & $\mathrm{K}_{b}\left[\mathrm{x} 10^{4} \mathrm{~L} \mathrm{~mol}^{-1}\right]^{\mathrm{b}}$ & $\mathrm{R}^{2 \mathrm{a}}$ & $\Delta \mathrm{G}\left[\mathrm{kJ} \mathrm{mol}{ }^{-1}\right]^{\mathrm{b}}$ & $\Delta \mathrm{H}\left[\mathrm{kJ} \mathrm{mol}{ }^{-1}\right]$ & $\Delta{\mathrm{S}\left[\mathrm{mol}^{-1} \mathrm{~K}^{-1}\right]}$ \\
\hline Ácido clorogênico & $11,0 \pm 0,66$ & 0,992 & $-31,1 \pm 1,91$ & $24,2 \pm 4,24$ & $171 \pm 19,5$ \\
Ácido cafeico & $6,9 \pm 0,60$ & 0,995 & $-29,9 \pm 2,63$ & $23,2 \pm 4,12$ & $162 \pm 14,6$ \\
Ácido ferúlico & $3,1 \pm 0,15$ & 0,998 & $-27,8 \pm 1,41$ & $15,1 \pm 3,24$ & $133 \pm 10,9$ \\
Quercetina & $2,3 \pm 0,42$ & 0,981 & $-26,8 \pm 4,90$ & $36,2 \pm 4,20$ & $194 \pm 13,3$ \\
\hline
\end{tabular}

${ }^{\mathrm{a}} \mathrm{R}^{2}$ - coeficiente de correlação; ${ }^{\mathrm{b} O s}$ valores de $K_{b}$ e $\Delta \mathrm{G}$ foram calculados a $323 \mathrm{~K}$. 

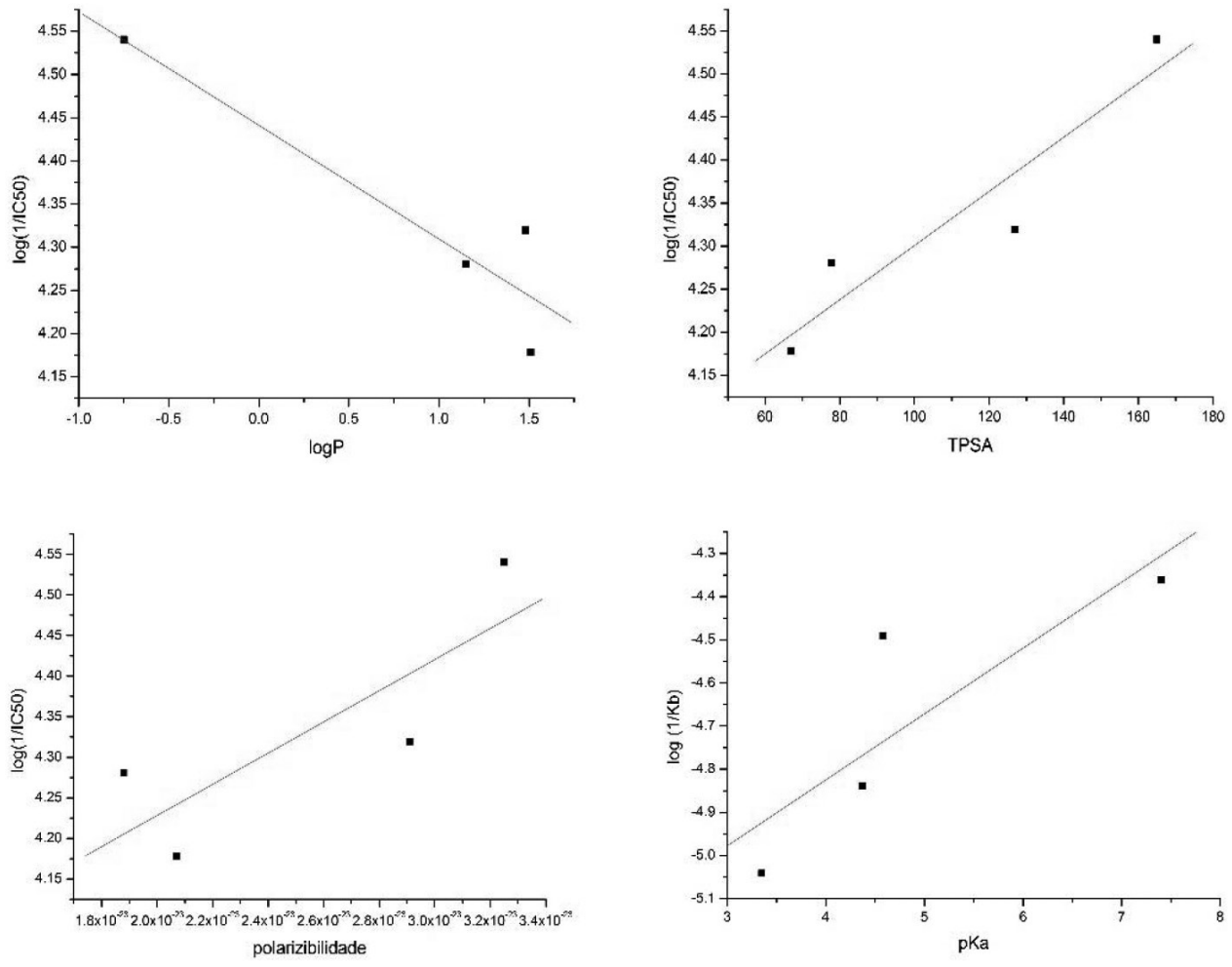

Figura 6. Relação de parâmetros encontrados nos ensaios de cinética e equilíbrio $\left(I C_{50}\right.$ e $\left.K_{b}\right)$ com descritores reportados para os polifenóis

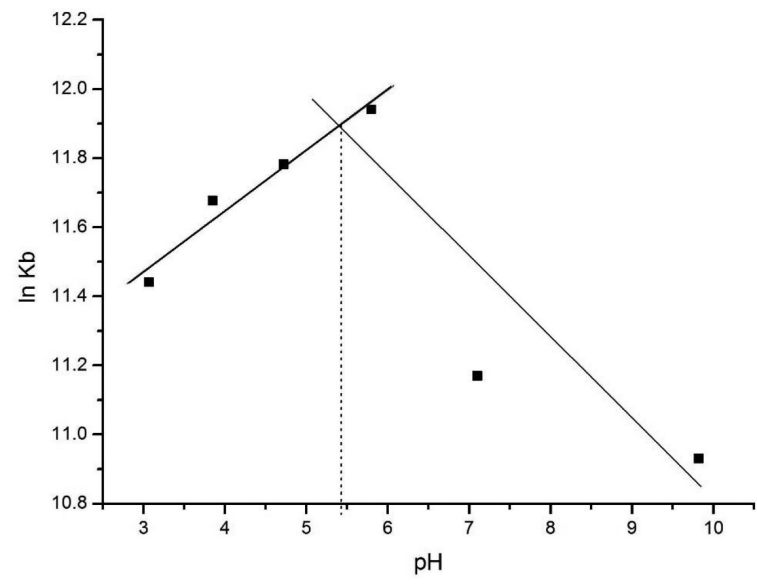

Figura 7. Interação de $\alpha$-amilase com ácido clorogênico em $323 \mathrm{~K}$ sob variação de $\mathrm{pH}$

A Figura 7 apresenta dois comportamentos lineares para a constante $K_{b}$ em função do $\mathrm{pH}$. Extrapolando-se linhas retas a partir desses resultados obtêm-se uma intersecção a 5,5 no eixo das abscissas coincidente com a faixa de pKa para His livre $(5,6$ a $7,0),{ }_{14}^{14}$ e reforçando-se a hipótese sugerida. De fato, a enzima possui três resíduos de His nos subsítios catalíticos, His 80, His 122 e His 210 , todos envolvidos em ligações de hidrogênio com o substrato em $\mathrm{pH} 7,5 .{ }^{21}$ No presente trabalho, os ensaios realizados em $\mathrm{pH}$ 5,9 sugerem a existência de uma população mínima de espécies carregadas positivamente para esses resíduos. Complementarmente, a Figura 6 sugere que a ligação de maior estabilidade com a enzima $\left(K_{b}\right)$ ocorreu para o ligante com maior intervalo entre o valor de pKa e o pH dos ensaios.

Os resultados obtidos da titulação espectrofluorimétrica de ácido clorogênico sob variação de força iônica (Figura 8) mostraram uma relação inversa na qual a estabilidade do complexo reduz em função do teor salino. ${ }^{31} \mathrm{O}$ gradiente negativo resultante do efeito da adição do sal neutro na interação ligante-proteína indica que os íons reagentes (ligante e proteína) exibem sinais contrários, reforçando a hipótese de estabilização dos complexos por interação eletrostática do carboxilato do ácido clorogênico à proteína. Como a enzima apresenta um valor de ponto isoelétrico (pI) em torno de 4,5, ${ }^{32} \mathrm{o}$ pH 5,9 utilizado nos ensaios implica que a mesma se apresentou na forma aniônica. ${ }^{33}$ De fato, utilizando-se uma calculadora virtual de propriedades físico-químicas para a sequência primária da enzima (Innovagen, http://www.pepcalc.com), ${ }^{22}$ foi contabilizado o valor de -14 para a rede de carga líquida da enzima no $\mathrm{pH}$ 5,9 do ensaio, e valor de pI de 4,15. Entretanto, são encontrados em torno dos subsítios de catálise da enzima seis resíduos de aminoácidos básicos (Arg, Lys e His) e apenas dois resíduos ácidos (Asp), ${ }^{21}$ o que pode contribuir para a interação do carboxilato do ácido clorogênico, tendo em vista os valores de $\mathrm{pK}$ das cadeias laterais dos aminoácidos livres de 9,4 para Lys ( $\left(\right.$-amino) e de 12,1 para Arg (grupo guanidínio). ${ }^{14}$ Esse dado também apoia a possibilidade de interação do ligante ionizado com

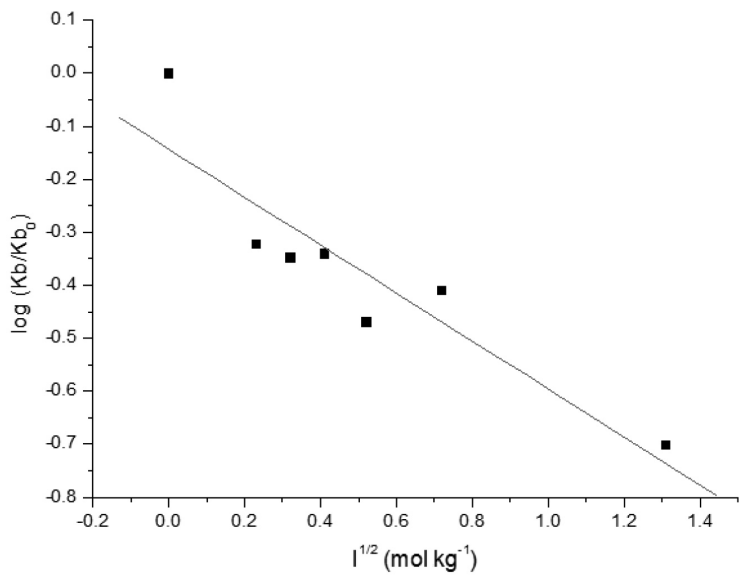

Figura 8. Interação de a-amilase com ácido clorogênico em $323 \mathrm{~K}$ sob variação de força iônica 
aminas imidazólicas de resíduos de His nos subsítios catalíticos da enzima (His 80, His 122 e His 210). ${ }^{21}$

\section{CONCLUSÃO}

Os polifenóis testados em diferentes temperaturas apresentaram potencial de inibição crescente frente a catálise da $\alpha$-amilase até 323 K. O ácido clorogênico foi o que apresentou maior estabilidade na formação dos complexos, com menor valor de Kic, maior sensibilidade com a temperatura e maior inibição na temperatura ótima da enzima $(323 \mathrm{~K})$. A interação dos polifenóis com $\alpha$-amilase revelou valores de $K_{b}$ crescentes com a temperatura, e os parâmetros termodinâmicos $\Delta H$ e $\Delta S$ indicaram um mecanismo entropicamente dirigido para a associação. O estudo da relação estrutura-atividade demonstrou uma correlação positiva entre a atividade biológica da $\alpha$-amilase (ligação e catálise) com os descritores de natureza polar dos polifenóis, sugerindo um mecanismo de estabilização dos complexos por interação eletrostática entre o íon carboxilato dos ligantes com o sítio ativo da enzima, e que foi corroborado variando-se o $\mathrm{pH}$ e a força iônica nos ensaios. Como um todo, os resultados apresentados sugerem que o procedimento de mosturação para a elaboração de cerveja pode ser influenciado pela inibição de polifenois intrínsecos do malte nas faixas de temperatura empregadas no processo.

\section{REFERÊNCIAS}

1. Bakkialakshmi, S.; Shanthi, B.; Bhuvanapriya, T.; Spectrochim. Acta, Part A 2012, 90, 12.

2. http://www.sebraemercados.com.br/wp-content/ uploads/2015/12/2014_05_20_RT_Mar_Agron_Cerveja_pdf.pdf, acessada em novembro 2016

3. https://sebrae.com.br/sites/PortalSebrae/artigos/microcervejariasganham-espaco-no-mercado-nacional,fbe9be300704e410VgnVCM10 00003b74010aRCRD, acessada em abril de 2017.

4. Bamforth, C.; Brewing materials and processes: A practical approach to beer excellence, $1^{\text {th }}$ ed., Academic Press: California, 2016.

5. Briggs, D. E.; Brookes, P. A.; Stevens, R.; Boulton, C. A.; Brewing: science and practice, $1^{\text {th }}$ ed., CRC Press: New York, 2004.

6. MacGregor, E. A.; Janeček, Š.; Svensson, B.; Biochim. Biophys. Acta, Protein Struct. Mol. Enzymol. 2001, 1546, 1.

7. Gonçalves, R.; Mateus, N.; De Freitas, V.; Food Chem. 2011, 125, 665.

8. He, Q.; Lv, Y.; Yao, K.; Food Chem. 2007, 101, 1178.
9. Hill, G. A.; Macdonald, D. G.; Lang, X.; Biotechnol. Lett. 1997, 19, 1139.

10. Aron, P. M.; Shellhammer, T. H.; J. Inst. Brew. 2010, 116, 369.

11. Collin, S.; Jerkovic, V.; Bröhan, M.; Callemien, D.; Nat. Prod. 2013, 1, 2333.

12. Marova, I.; Parilova, K.; Friedl, Z.; Obruca, S.; Duronova, K.; Chromatographia 2011, 73, 83.

13. Bisswanger, H; Enzyme kinetics: principles and methods, $2^{\text {th }}$ ed., John Wiley \& Sons: Weinhein, 2008.

14. Marangoni, A. G.; Enzyme kinetics: a modern approach, $1^{\text {th }}$ ed., John Wiley \& Sons: New Jersey, 2003.

15. Valeur, B.; Berberan-Santos, M. N.; Molecular fluorescence: principles and applications, $2^{\text {th }}$ ed., Wiley-VCH: Weinhein, 2012.

16. Gore, M. G.; Spectrophotometry and spectrofluorimetry: a practical approach, $2^{\text {th }}$ ed., Oxford University Press: New York, 2000.

17. Trnková, L.; Bousova, I.; Kubicek, V.; Drsata, J.; Natural Science 2010 , 2,563 .

18. Rashidipour, S.; Naeeminejad, S.; Chamani, J.; J. Biomol. Struct. Dyn. 2016, 34, 57.

19. Van de Weert, M.; Stella, L.; J. Mol. Struct. 2011, 998, 144.

20. Atkins, P.; De Paula, J.; Physical chemistry for the life sciences, $2^{\text {th }}$ ed., Oxford University Press: USA, 2011.

21. Brzozowski, A. M.; Davies, G. J.; Biochemistry 1997, 36, 10837.

22. http://www.uniprot.org/uniprot/, acessada em outubro 2016.

23. Sun, L.; Chen, W.; Meng, Y.; Yang, X.; Yuan, L.; Guo, Y.; Food Chem. 2016, 208, 51.

24. Hu, Y. J.; Chen, C. H.; Zhou, S.; Bai, A. M.; Ou-Yang, Y.; Mol. Biol. Rep. 2012, 39, 2781.

25. Ross, P. D.; Subramanian, S.; Biochemistry 1987, 20, 3096.

26. Šeruga, M.; Tomac, I.; Int. J. Electrochem. Sci. 2014, 9, 6134.

27. Ozkorucuklu, S. P.; Beltrán, J. L.; Fonrodona, G.; Barrón, D.; Alsancak, G.; Barbosa, J.; J. Chem. Eng. Data 2009, 54, 807.

28. Rojas-Romo, C.; Serrano, N.; Ariño, C.; Arancibia, V.; Díaz-Cruz, J. M.; Esteban, M.; Talanta 2016, 155, 21.

29. https://pubchem.ncbi.nlm.nih.gov/compound/quercetin\#section=Top, acessada em abril de 2017.

30. Cer, R. Z.; Mudunuri, U.; Stephens, R.; Lebeda, F. J.; Nucleic Acids Res. 2009, 37, 441.

31. Bunton, C. A.; Robinson, L. B.; J. Org. Chem. 1969, 34, 780.

32. Altikatoglu, M.; Tavukcuoglu, Ö.; Mustafaev, M.; Protein J. 2010, 29, 120.

33. Deshpande, S. S.; Cheryan, M.; J. Food Sci. 1984, 49, 516. 